\title{
Molecular variation among virulent and avirulent strains of the quarantine nematode Bursaphelenchus xylophilus
}

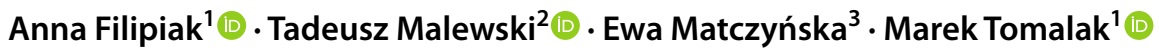

Received: 2 September 2020 / Accepted: 14 October 2020 / Published online: 10 November 2020

(c) The Author(s) 2020

\begin{abstract}
Bursaphelenchus xylophilus is an emerging pathogenic nematode that is responsible for a devastating epidemic of pine wilt disease worldwide, causing severe ecological damage and economic losses to forestry. Two forms of this nematode have been reported, i.e., with strong and weak virulence, commonly referred as virulent and avirulent strains. However, the pathogenicity-related genes of $B$. xylophilus are not sufficiently characterized. In this study, to find pathogenesis related genes we re-sequenced and compared genomes of two virulent and two avirulent populations. We identified genes affected by genomic variation, and functional annotation of those genes indicated that some of them might play potential roles in pathogenesis. The performed analysis showed that both avirulent populations differed from the virulent ones by 1576 genes with high impact variants. Demonstration of genetic differences between virulent and avirulent strains will provide effective methods to distinguish these two nematode virulence forms at the molecular level. The reported results provide basic information that can facilitate development of a better diagnosis for B. xylophilus isolates/strains which present different levels of virulence and better understanding of the molecular mechanism involved in the development of the PWD.
\end{abstract}

Keywords Pine wood nematode $\cdot$ Pine wilt disease $\cdot$ Next-generation sequencing $\cdot$ Genome variation $\cdot$ GO-enrichment analysis

\section{Introduction}

Pine wilt disease (PWD) is one of the most serious global tree diseases affecting coniferous forests around the world. It is caused by the pine wood nematode (PWN), Bursaphelenchus xylophilus (Nematoda: Aphelenchoididae) (Mota and Vieira 2008; Jones et al. 2013). This nematode is listed as

Communicated by Stefan Hohmann.

Electronic supplementary material The online version of this article (https://doi.org/10.1007/s00438-020-01739-w) contains supplementary material, which is available to authorized users.

Anna Filipiak

A.Filipiak@iorpib.poznan.pl

1 Department of Biological Pest Control, Institute of Plant Protection, National Research Institute, Władysława Węgorka 20, 60-318 Poznan, Poland

2 Department of Molecular and Biometric Techniques, Museum and Institute of Zoology, Polish Academy of Sciences, Wilcza 64, 00-679 Warsaw, Poland

3 Genomed SA, Ponczowa 12, 02-971 Warsaw, Poland a major plant quarantine organism for most countries in the world (Evans et al. 1996; Futai 2013). B. xylophilus is native to North America where it causes only a limited damage to native pines, although non-native species are profoundly affected (Jones et al. 2013). PWN was introduced into Japan during the early twentieth century and it spread subsequently to other East Asian (China, Taiwan, South Korea) and European (Portugal, Spain) countries (Mota et al. 1999; Robertson et al. 2011; Futai 2013; Ding et al. 2016; Filipiak et al. 2017). The nematodes are transmitted to healthy trees by longhorn beetles in the genus Monochamus, during maturation feeding of the insect (Togashi and Shigesada 2006). Once B. xylophilus enters the pine tree, it migrates through the resin canals, destructively feeding on the parenchymal cells (Shinya et al. 2013). In many regions worldwide pine is among the most important tree genera for the forest industry and the rapid spread of this disease has become a major problem (Mota and Vieira 2008; Vicente et al. 2012; Espada et al. 2016). Every year thousands of trees displaying symptoms of PWD are felled and removed in the affected areas. $B$. xylophilus causes the death of host trees in less than one year after infection under suitable environmental conditions, and 
the risk of this problem is likely to increase due to climate changes (Pereira et al. 2013; Qiu et al. 2013).

Earlier research provided evidence that B. xylophilus could effectively compete for the host tree and vector insects with native species $B$. mucronatus, and reduce or displace it from the original locations (Futai 1980; Cheng et al. 2009). However, in our in vitro and in vivo research conducted in plate cultures of Botryotinia fuckeliana and pine seedlings, respectively, a range of variation in results of such competition was observed among particular isolates of these two competing nematodes (Tomalak and Filipiak 2013).

Kiyohara and Bolla (1990) reported a great variation in the virulence level of $B$. xylophilus collected throughout Japan. Mortality of pine seedlings ranged from 0 to $100 \%$ and the virulence of nematode isolates from a single stand of pines also varied significantly. With respect to pathogenicity, two major groups of strains, i.e., virulent and avirulent, have been reported in B. xylophilus (Bolla and Boschert 1993; Akiba et al. 2012). To date, many studies have reported that the virulence level of B. xylophilus is associated with its reproductive potential and population growth ability (Kiyohara and Bolla 1990; Aikawa et al. 2003; Wang et al. 2005; Aikawa and Kikuchi 2007; Shinya et al. 2012; Qiu et al. 2013; Filipiak 2015). The generation time of virulent isolates cultured virulent on B. fuckeliana at $25{ }^{\circ} \mathrm{C}$ was shorter than that of avirulent isolates and the rate of population increase was faster than in the avirulent isolates (Wang et al. 2005). In the in vivo situation, when virulent and avirulent isolates were separately inoculated into Pinus thunbergii seedlings, nematode density of the virulent population increased with time after inoculation, while the avirulent isolate never reproduced (Kiyohara and Bolla 1990; Aikawa and Kikuchi 2007). Thus, the results of the earlier studies suggest that virulence is closely associated with the nematode reproductive potential, irrespective of in vitro or in vivo conditions.

In PWD the mechanism of pathogenicity is complicated and involves many pathogenic factors including host pines, nematodes, beetles, fungi, bacteria, environmental factors, and other aspects (Shinya et al. 2013). A draft genome sequence of B. xylophilus was reported in 2011 (Kikuchi et al. 2011). Its availability should facilitate additional studies on B. xylophilus pathogenicity. To date, however, only a few transcriptome-type studies (Espada et al. 2016; Li et al. 2019, 2020; Hu et al. 2020) and only one genome-wide analysis (Palomares-Rius et al. 2015) have been reported.

The main objective of this study was to reveal genetic differences related to pathogenicity of B. xylophilus. It was achieved by resequencing of four $B$. xylophilus strains followed by comparison and analysis of the complete nuclear genome sequences of two virulent (BxPt67OL and BxMad24C) and two avirulent (C14-5 and OKD-1) populations of this nematode.

\section{Materials and methods}

\section{Nematode strains}

In the reported study, two virulent and two avirulent strains of B. xylophilus were examined. The origin and ecological features of the nematode strains are summarized in Table 1.

The avirulent "C14-5" and "OKD-1" strains were kindly supplied by Dr. Y. Takeuchi from Kyoto University, Japan. The virulent "BxMad24C" and "BxPt67OL" strains were provided by Prof. M. Mota from the University of Évora, Portugal.

The virulence of the strains was demonstrated by previous inoculation tests on pine seedlings (Aikawa et al. 2003; Filipiak 2015). Prior to the examination, all strains were cultured on B. fuckeliana/potato dextrose agar at $25^{\circ} \mathrm{C}$ for ca. 2 weeks. Propagated nematodes were stored in $20 \mu \mathrm{l}$ distilled $\mathrm{H}_{2} \mathrm{O}$ at $-20{ }^{\circ} \mathrm{C}$ until being used for subsequent DNA extraction.

\section{Genomic DNA preparation and sequencing}

Genomic DNA of nematodes was isolated with a QIAamp DNA Micro Kit (Qiagen, Hilden, Germany) according to the protocol provided by the manufacturer. DNA concentration and its purity were measured using a NanoDrop spectrophotometer (Thermo Fisher Scientific Inc., MA, USA). 50-100 ng of DNA was used to construct 350-bp libraries, using a TruSeq Nano DNA Library Prep Kit (Illumina, San Diego, USA) with the standard protocol. Libraries were sequenced on an Illumina HiSeqX Ten, according to the manufacturer's recommended protocol, to produce 150-bp paired end reads (Genomed, Warsaw, Poland).

\section{Data analysis}

The quality of the obtained raw sequencing data was first assessed by FastQC (Andrews 2010; https://www.bioinforma tics.babraham.ac.uk/projects/fastqc). Subsequently, adapters and low quality bases were removed by Trimmomatic in paired-end mode (Bolger et al. 2014). For downstream

Table 1 Origin of Bursaphelenchus xylophilus strains used in the study, and their virulence

\begin{tabular}{llc}
\hline Strain name & Geographical origin & Virulence \\
\hline BxPt67OL & Portugal & Virulent \\
BxMad24C & Madeira, Portugal & Virulent \\
C14-5 & Chiba, Japan & Avirulent \\
OKD-1 & Okayama, Japan & Avirulent \\
\hline
\end{tabular}


analyses, only reads of a minimum length of $30 \mathrm{bp}$ and Phred score $>30$ were used.

\section{Mapping}

For each strain, Illumina reads were mapped to the B. xylophilus reference $\mathrm{Ka} 4 \mathrm{C} 1$ strain genome (GCA_000231135.1) using Burrows-Wheeler Aligner (Li and Durbin 2009). Single nucleotide variants (SNVs) and small indels were determined using GATK HaplotypeCaller (Van der Auwera et al. 2013; https://gatk.broadinstitute.org/hc/en-us). Only variants with minimal Phred quality 30 and minimal coverage of $4 \times$ where subjected for further analysis.

\section{Variant effect analysis}

Variant consequences for genes where evaluated with the ensembl variant effect predictor (VEP) (McLaren et al. 2016). Then, genes with one high impact variant which were present in at least one virulent populations, but absent in any of the avirulent populations were selected. Similarly, genes present in at least one avirulent population but absent in virulent ones were selected for further analysis. The calculations for each set of genes were made using in-house Linux tools and Python scripts. This approach allowed for identification of gene sets, which were further examined with Gene Ontology enrichment analysis.

\section{GO-enrichment analysis}

The WormBase database was used to determine the nematode gene annotations related to their functions (Gene Ontology Consortium 2004; https://geneontology.org/ docs/ontology-documentation). Subsequently, using the topGO package from the $\mathrm{R}$ environment (https://bioco nductor.org/packages/release/bioc/html/topGO.html), GOenrichment analyzes were performed for both of the above gene sets. The topGO package is designed to facilitate semi-automated enrichment analysis for Gene Ontology (GO) terms. Each GO category (molecular function-MF, cellular component- $\mathrm{CC}$, biological process-BP) is tested independently. GO enrichment analysis allows testing the over-representation of GO terms. In our study, we used two methods, i.e., the classic and elim, to identify the over-representation of GO terms (Alexa and Rahnenfuhrer 2018). The classic method analyzes GO identifiers in a standard way, in isolation from their hierarchical structure, therefore, it often reports more general GO terms as statistically significant. The elim method was designed to be more conservative then the classic method and therefore one expects the $p$ values returned by the former method are lower bounded by the $p$ values returned by the later method. Moreover, it tries to take into account the hierarchy of GO terms and focus on the most specific ones (Alexa et al. 2006; Alexa and Rahnenfuhrer 2018). In our analysis, we focused on statistically significant GO terms, indicated by $p$ values below the standard significance level alpha $=0.05$ and with more than 5 significant genes for both Fisher classic and Fisher elim methods (except for several GO terms with $\leq 5$ significant genes, but substantially lower $p$ values $(p<0.01)$, which are also shown in Table 3). Genes characterized by those GO terms demonstrated higher incidence in the analyzed gene set, than it would be expected at random.

\section{Results}

\section{Sequencing}

In order to investigate the genetic differences between virulent and avirulent $B$. xylophilus populations, four representative strains with different pathogenic traits were resequenced. After sequencing and filtering of low quality bases ca. 37 millions of read pairs for both the virulent populations (BxPt67OL and BxMad24C), and ca. 37 and ca. 35 millions of read pairs for the avirulent populations (C14-5 and OKD1 , respectively) have been obtained (Table 2). The obtained sequences were deposited at NCBI Sequence Read Archive (SRA) under accession number PRJNA630377.
Table 2 Summary of sequencing, clustering, and annotation results

\begin{tabular}{|c|c|c|c|c|}
\hline \multirow[t]{2}{*}{ Parameter } & \multicolumn{2}{|l|}{ Virulent } & \multicolumn{2}{|l|}{ Avirulent } \\
\hline & BxPt67OL & BxMad24C & $\mathrm{C} 14-5$ & OKD-1 \\
\hline Number of read pairs & $37,299,205$ & $37,227,358$ & $37,160,862$ & $35,259,088$ \\
\hline Number of mapped reads & $24,574,325$ & $66,300,708$ & $43,722,336$ & $10,636,716$ \\
\hline$\%$ of mapped reads & 32.70 & 87.29 & 57.67 & 15.01 \\
\hline Coverage & $36.0 x$ & $111.1 \mathrm{x}$ & $66.7 x$ & $13.7 \mathrm{x}$ \\
\hline Sequence variants (GATK) & $1,161,206$ & $1,049,303$ & $2,156,336$ & $1,926,667$ \\
\hline High impact variants & 5142 & 4102 & 8220 & 9090 \\
\hline $\begin{array}{l}\text { Number of genes with high } \\
\text { impact variants }\end{array}$ & 2324 & 1838 & 3578 & 3831 \\
\hline
\end{tabular}


Table 3 Enriched statistically significant GO terms $(p<0.05)$ for two avirulent and two virulent populations (the results are presented in ascending order according to Fisher's $p$ value for the elim method)

\begin{tabular}{|c|c|c|c|c|c|c|c|c|c|}
\hline Form & GO category & GO identifier & Term & Annotated & Significant & Expected & $\begin{array}{l}\text { Rank in } \\
\text { classic } \\
\text { Fisher }\end{array}$ & elim Fisher & classic Fisher \\
\hline \multirow[t]{19}{*}{ Avirulent } & \multirow[t]{19}{*}{$\begin{array}{r}\text { Molecular } \\
\text { function }\end{array}$} & GO:0004190 & $\begin{array}{l}\text { Aspartic-type endo- } \\
\text { peptidase activity }\end{array}$ & 113 & 21 & 7.87 & 5 & 0.000028 & 0.000028 \\
\hline & & GO:0005272 & $\begin{array}{l}\text { Sodium channel } \\
\text { activity }\end{array}$ & 54 & 12 & 3.76 & 8 & 0.00026 & 0.000026 \\
\hline & & GO:0046923 & $\begin{array}{l}\text { ER retention } \\
\text { sequence binding }\end{array}$ & 3 & 3 & 0.21 & 9 & 0.00034 & 0.00034 \\
\hline & & GO:0004222 & $\begin{array}{l}\text { Metalloendopepti- } \\
\text { dase activity }\end{array}$ & 120 & 19 & 8.36 & 11 & 0.00058 & 0.00058 \\
\hline & & GO:0016298 & Lipase activity & 31 & 7 & 2.16 & 13 & 0.00462 & 0.00462 \\
\hline & & GO:0008271 & $\begin{array}{l}\text { Secondary active } \\
\text { sulfate transmem- } \\
\text { brane transporter } \\
\text { activity }\end{array}$ & 17 & 5 & 1.18 & 14 & 0.00493 & 0.00493 \\
\hline & & GO:0004198 & $\begin{array}{l}\text { Calcium-dependent } \\
\text { cysteine-type } \\
\text { endopeptidase } \\
\text { activity }\end{array}$ & 6 & 3 & 0.42 & 17 & 0.00574 & 0.00574 \\
\hline & & GO:0070011 & $\begin{array}{l}\text { Peptidase activity, } \\
\text { acting on L-amino } \\
\text { acid peptides }\end{array}$ & 522 & 73 & 36.37 & 2 & 0.00611 & 0.0000000029 \\
\hline & & GO:0043492 & $\begin{array}{l}\text { ATPase activity, } \\
\text { coupled to move- } \\
\text { ment of substances }\end{array}$ & 78 & 12 & 5.43 & 18 & 0.00728 & 0.00728 \\
\hline & & GO:0016820 & $\begin{array}{l}\text { Hydrolase activity, } \\
\text { acting on acid } \\
\text { anhydrides, cata- } \\
\text { lyzing transmem- } \\
\text { brane movement } \\
\text { of substances }\end{array}$ & 74 & 11 & 5.16 & 20 & 0.01281 & 0.01281 \\
\hline & & GO:0042626 & $\begin{array}{l}\text { ATPase activity, } \\
\text { coupled to trans- } \\
\text { membrane move- } \\
\text { ment of substances }\end{array}$ & 74 & 11 & 5.16 & 21 & 0.01281 & 0.01281 \\
\hline & & GO:0015399 & $\begin{array}{l}\text { Primary active } \\
\text { transmembrane } \\
\text { transporter activity }\end{array}$ & 75 & 11 & 5.23 & 22 & 0.01411 & 0.01411 \\
\hline & & GO:0015405 & $\begin{array}{l}\text { P-P-bond- } \\
\text { hydrolysis-driven } \\
\text { transmembrane } \\
\text { transporter activity }\end{array}$ & 75 & 11 & 5.23 & 23 & 0.01411 & 0.01411 \\
\hline & & GO:0004620 & $\begin{array}{l}\text { Phospholipase } \\
\text { activity }\end{array}$ & 30 & 6 & 2.09 & 26 & 0.01568 & 0.01568 \\
\hline & & GO:0050660 & $\begin{array}{l}\text { Flavin adenine dinu- } \\
\text { cleotide binding }\end{array}$ & 57 & 9 & 3.97 & 27 & 0.01611 & 0.01611 \\
\hline & & GO:0008233 & Peptidase activity & 546 & 78 & 38.04 & 1 & 0.01626 & 0.00000000027 \\
\hline & & GO:0017171 & $\begin{array}{l}\text { Serine hydrolase } \\
\text { activity }\end{array}$ & 80 & 11 & 5.57 & 29 & 0.0221 & 0.0221 \\
\hline & & GO:0008236 & $\begin{array}{l}\text { Serine-type pepti- } \\
\text { dase activity }\end{array}$ & 80 & 11 & 5.57 & 30 & 0.0221 & 0.0221 \\
\hline & & GO:0004180 & $\begin{array}{l}\text { Carboxypeptidase } \\
\text { activity }\end{array}$ & 37 & 6 & 2.58 & 33 & 0.04077 & 0.04077 \\
\hline
\end{tabular}


Table 3 (continued)

\begin{tabular}{|c|c|c|c|c|c|c|c|c|c|}
\hline Form & GO category & GO identifier & Term & Annotated & Significant & Expected & $\begin{array}{l}\text { Rank in } \\
\text { classic } \\
\text { Fisher }\end{array}$ & elim Fisher & classic Fisher \\
\hline & Biological & GO:0006508 & Proteolysis & 648 & 86 & 45.74 & 1 & 0.0000000013 & 0.0000000013 \\
\hline & & GO:0006621 & $\begin{array}{l}\text { Protein retention in } \\
\text { ER lumen }\end{array}$ & 3 & 3 & 0.21 & 2 & 0.00035 & 0.00035 \\
\hline & & GO:0035725 & $\begin{array}{l}\text { Sodium ion } \\
\text { transmembrane } \\
\text { transport }\end{array}$ & 67 & 12 & 4.73 & 5 & 0.00221 & 0.00221 \\
\hline & & GO:1902358 & $\begin{array}{l}\text { Sulfate transmem- } \\
\text { brane transport }\end{array}$ & 16 & 5 & 1.13 & 7 & 0.00389 & 0.00389 \\
\hline & & GO:0009435 & $\begin{array}{l}\text { NAD biosynthetic } \\
\text { process }\end{array}$ & 6 & 3 & 0.42 & 10 & 0.00594 & 0.00594 \\
\hline & & GO:0071103 & $\begin{array}{l}\text { DNA conformation } \\
\text { change }\end{array}$ & 44 & 8 & 3.11 & 18 & 0.0107 & 0.0107 \\
\hline & $\begin{array}{l}\text { Cellular } \\
\text { component }\end{array}$ & GO:0016021 & $\begin{array}{l}\text { Integral component } \\
\text { of membrane }\end{array}$ & 4378 & 362 & 320.74 & 1 & 0.0000089 & 0.0000089 \\
\hline \multirow[t]{5}{*}{ Virulent } & $\begin{array}{r}\text { Molecular } \\
\text { function }\end{array}$ & GO:0016491 & $\begin{array}{l}\text { Oxidoreductase } \\
\text { activity }\end{array}$ & 483 & 19 & 9.58 & 1 & 0.003 & 0.003 \\
\hline & & GO:0020037 & Heme binding & 120 & 7 & 2.38 & 2 & 0.0096 & 0.0096 \\
\hline & & GO:0048037 & Cofactor binding & 153 & 7 & 3.03 & 10 & 0.032 & 0.032 \\
\hline & $\begin{array}{c}\text { Biological } \\
\text { process }\end{array}$ & GO:0055114 & $\begin{array}{l}\text { Oxidation-reduction } \\
\text { process }\end{array}$ & 521 & 19 & 10.76 & 1 & 0.0097 & 0.0097 \\
\hline & $\begin{array}{l}\text { Cellular } \\
\text { component }\end{array}$ & GO:0016020 & Membrane & 4608 & 114 & 98.91 & 1 & 0.0019 & 0.0019 \\
\hline
\end{tabular}

GO identifier (GO.ID) identifier Gene Ontology, Term description of the GO identifier, Annotated the number of analyzed genes with a given GO identifier, Significant the number of genes belonging to the set genes with a given GO identifier, Expected the expected number of genes with a given GO identifier under condition that it is not statistically more frequent than in the set all genes with GO identifiers, Rank in classic Fisher Ranking of a given GO identifier by Fisher's $p$ value for the classic method, elim Fisher Fisher's $p$ value for the elim method, classic Fisher Fisher's $p$ value for the classic method 
After mapping to the B. xylophilus reference genome, for the virulent populations BxPt67OL and BxMad24C ca. $3.7 \mathrm{~Gb}$ and ca. $9.9 \mathrm{~Gb}$ paired end data were obtained, respectively. For the avirulent populations C14-5 and OKD-1 ca. $6.6 \mathrm{~Gb}$ and ca. $1.6 \mathrm{~Gb}$ paired end data were obtained, respectively. Overall, $32.70 \%$ and $87.29 \%$ reads of the virulent populations (BxPt67OL and BxMad24C, respectively) and $57.67 \%$ and $15.01 \%$ of the avirulent populations (C14-5 and OKD-1, respectively) were successfully aligned to the B. xylophilus genome. Variable levels of mapping of the examined populations to the B. xylophilus reference genome were due to the presence of random bacterial sequences in extracted DNA. Unmapped reads were analysed with the Kraken program (Wood and Salzberg 2014). The performed analysis showed that virulent populations BxPt67OL and BxMad24C contained $34.85 \%$ and $10.46 \%$ while the avirulent populations C14-5 and OKD-1 contained 27.93 and $56.53 \%$ reads assigned to the bacteria, respectively. Unfortunately, the share of bacterial data resulted in less available data derived from nematodes and, consequently, less coverage, especially for the population OKD-1.

\section{Sequence variants}

The program GATK HaplotypeCaller has determined the sequence variants based on the paired-end reads mapped to the B. xylophilus reference genome. The genomes of B. xylophilus were found to be highly variable comparing to reference $\mathrm{Ka} 4 \mathrm{C} 1$ strain; 1,161,206 and 1,049,303 variant positions for virulent BxPt67OL and BxMad24C, and 2,156,336 and 1,926,667 for avirulent C14-5 and OKD-1 populations were detected, respectively (Table 2). The results of the analysis showed that avirulent populations had $1.8 \times$ more variants than virulent ones. The $B$. xylophilus reference genome corresponds to the virulent population, therefore the detection of fewer variants for the virulent populations seems to be as expected.

The ensembl variant effect predictor (VEP) program revealed the presence of variants with significant consequences for the protein function (i.e., high impact variants). Significant differences were found between virulent and avirulent populations. While the virulent BxPt67OL and BxMad24C populations had 5142 and 4102 high impact variants comparing to $\mathrm{Ka} 4 \mathrm{C} 1$ strain, the avirulent $\mathrm{C} 14-5$ and OKD-1 had 8220 and 9090 high impact variants, respectively. Moreover, 2324 (BxPt67OL) and 1838 (BxMad24C) genes with high-impact variants were identified in virulent populations, and 3578 (C14-5) and 3831 (OKD-1) genes were identified in avirulent populations, respectively (Table 2; Table ESM1). Both analysed virulent populations differed from the reference strain by 469 genes with highimpact variants, while both avirulent populations differed by as many as 1576 genes (Table ESM1).

\section{GO-enrichment analysis}

For the above genes, functional annotation was performed with topGO against Wormbase database to assign it to B. xylophilus molecular functions, biological processes and cellular components. Currently, 17,704 B. xylophilus genes are annotated in WormBase (WS277 release). In the presently reported research nematode gene annotations for 10,438 genes were determined (Table ESM2). For the avirulent populations, the GO identifiers distinguished 6 biological processes, 19 molecular functions and 1 cellular component for the avirulent populations, while for the virulent populations, the GO analysis distinguished 1 biological process, 3 molecular functions, and 1 cellular component (Table 3). For each GO category, genes associated with molecular functions, biological processes, and cellular components were also identified and presented in Tables ESM3, ESM4, ESM5, ESM6, ESM7 and ESM8.

For the biological processes, proteolysis, protein retention in ER lumen, sodium ion transmembrane transport, sulfate transmembrane transport, NAD biosynthetic process, and DNA conformation change were significantly enriched in the avirulent populations, whereas only oxidation-reduction process was enriched in the virulent populations.

For the avirulent populations, most highly represented terms of gene ontology (GO) in the molecular function category were related to endopeptidases (aspartic-type endopeptidase activity, metalloendopeptidase activity, calcium-dependent cysteine-type endopeptidase activity, peptidase activity and peptidase activity: acting on L-amino acid peptides) and other peptidases (serine-type peptidase activity, carboxypeptidase activity). The other molecular functions belonged to sodium channel activity, ER retention sequence binding, lipase activity, secondary active sulfate transmembrane transporter activity, ATPase activity: coupled to movement of substances and coupled to transmembrane movement of substances, hydrolase activity: acting on acid anhydrides and catalyzing transmembrane movement of substances, primary active transmembrane transporter activity, P-P-bond-hydrolysis-driven transmembrane transporter activity, phospholipase activity, flavin adenine dinucleotide binding, and serine hydrolase activity, whereas for the virulent populations oxidoreductase activity, heme binding, and cofactor binding were recorded.

For the cellular component, only integral component of membrane was significantly enriched in the avirulent populations, and in the virulent populations only membrane was found (Table 3).

\section{Discussion}

The virulence mechanisms of $B$. xylophilus is complicated and involves many factors. It is suggested that B. xylophilus may use different genes or pathways to overcome the pine 
antinematodal response (Sommer and Streit 2011; Santos et al. 2012; Figueiredo et al. 2013). One of the approach to elucidate these mechanisms is whole-genome sequencing (Li et al. 2009).

In our study, four representative populations of B. xylophilus, two each of virulent and avirulent phenotypes, which originated from Japan and Portugal, respectively, were selected. All those populations presented different phenotypic or ecological traits and they had already been used in several previous studies (Aikawa et al. 2003; Filipiak 2015). The examined populations were closely related, and they shared some similar characteristics within the virulence category, including faster and slower development throughout the life cycle, in virulent (BxPt67OL and BxMad24C) and avirulent (C14-5 and OKD-1) populations, respectively.

Our genome-wide analysis revealed that virulent populations of $B$. xylophilus has high level of genome variation (BxPt67OL-1.56\% and BxMad24C-1.41\% comparing to reference genome). Differences were bigger when we compared avirulent populations to reference genome (C14-5$2.91 \%$ and OKD-1-2.60\%). Obtained data are in line with genomic inter-strain differences reported by Palomares-Rius et al. (2015). It seemed that the level of diversity in the $B$. xylophilus genome was high but similar situation had been also observed in other hyper-diverse organisms, including nematodes (e.g., Caenorhabditis brenneri or C. remanei) (Cutter et al. 2013; Palomares-Rius et al. 2015; Ding et al. 2016). Previous studies indicated that organisms with large population size, short generation time, and small body size were more likely to be hyper-diverse (Cutter et al. 2013). $B$. xylophilus presents all the aforementioned characters. It is also possible to find some sequence polymorphisms among different B. xylophilus isolates originating from a local area (Ding et al. 2016).

Our genome analysis revealed also the presence of bacterial sequences in the sequencing data. It has previously been confirmed that $B$. xylophilus is associated with a range of bacterial species which might form an important component of the infection process (Vicente et al. 2012; Espada et al. 2016). A number of random bacteria is also frequently present in the nematode laboratory cultures. However, in this study we did not focus on this issue.

In the presently reported study, Gene Ontology (GO) was enriched in 6 terms involved in biological processes, 19 terms in molecular functions, and 1 term in cellular component for avirulent populations. In contrast, for virulent populations, Gene Ontology (GO) was enriched in 1 term involved in biological processes, 3 terms in molecular functions, and 1 term in cellular component. All these enriched terms were statistically significant $(p<0.05)$. The conducted study revealed that the examined avirulent populations contained more high impact variants and all GO categories (i.e., biological process, molecular function and cellular component) were significantly more enriched, especially those involved in molecular functions (Table 3).

Earlier research confirmed that the effective antioxidant ability is of critical importance in establishing the infection (Shinya et al. 2013; Vicente et al. 2015). Our study revealed that oxidoreductase activity (GO:0016491) and oxidation-reduction process (GO:0055114) were enriched in the virulent populations as statistically significant (Table 3 ). A high representation of these two terms may indicate a higher oxidative stress tolerance in virulent populations. In the early stages of invasion, B. xylophilus has to overcome host defense mechanisms, such as strong oxidative stress. It was previously confirmed that according to the functional annotation, some of the cell wall degradation-related genes were upregulated significantly. The oxidoreductase and hydrolase genes are considered to be key factors that allow B. xylophilus to invade its host (Qiu et al. 2013). Only successful, virulent nematodes are able to tolerate the plant defenses, and further migrate and proliferate inside of the host tree. However, it was also proved that different virulent B. xylophilus populations exhibited different tolerance to oxidative stress which is crucial component in host defense mechanisms (Vicente et al. 2015; Ding et al. 2016). Previous research suggested that catalases of highly virulent B. xylophilus were crucial for the nematode survival under prolonged exposure to oxidative stress in vitro (Vicente et al. 2015). Moreover, recent studies indicated that twelve antioxidant proteins were identified in the secretome of $B$. xylophilus. The secreted antioxidant enzymes would play an important role in B. xylophilus self-protection from oxygen free radicals in the pine tree (Kikuchi et al. 2011; Shinya et al. 2013; Ding et al. 2016).

To ensure successful infestation, B. xylophilus needs to break through pine host defense system. It is considered that reactive oxygen species (ROS) are to be the first line of defense in plants. Moreover, the suppression subtractive hybridization has revealed that the pathogenesis-related genes and cell wall-related genes induced by reactive oxygen species are crucial in the defense against PWN infestation (Nose and Shiraishi 2011; Hirao et al. 2012). Breaking down ROS defense also facilitate its ongoing and persistent infestations by weakening the resistance in host plants. ROS oxidize DNA, proteins, and lipids, which cause damage to organelles and inhibit cell functions in plant attackers. Among ROS, especially oxygen $\mathrm{H}_{2} \mathrm{O}_{2}$, is an important factor for regulation of host-nematode interactions and partly govern the success or failure of the disease ( $\mathrm{Li}$ et al. 2016). Many reports suggest that nematode surface coat protein plays various crucial roles in host-parasite interactions, including regulation of microbes' adhesion to the nematode's body surface, lubrication, elicitation of the host defense responses, and modulation to help counter host defense responses (Spiegel and McClure 1995; Gravato-Nobre and 
Evans 1998; Shinya et al. 2010). B. xylophilus produces also surface coat proteins to help protect itself from ROS (Shinya et al. 2010, 2013). The identified surface coat proteins contained a potential regulator of ROS production, and ROS scavengers. These functions seem to be essential for establishing their infection and causing sudden death of host pine trees by the PWD (Shinya et al. 2010).

Another studies revealed that after inoculation of virulent populations of $B$. xylophilus into resistant Japanese black pine (P. thunbergii) more frequent accumulation of phenolic compounds around the cortex resin canals was observed. It was suggested that this accumulation was a very effective defense against infection due to restricting migration of $B$. xylophilus (Ishida et al. 1993). Hirao et al. (2012) assessed the difference in expressed sequence tag (EST) transcript diversity of activated defense genes and differences in the timing and magnitude of expression of these genes between resistant and susceptible $P$. thunbergii trees following PWN inoculation. In susceptible trees after PWN inoculation, pathogenesis related genes and antimicrobial-related genes were rapidly induced to high levels within 1-day post-inoculation. In contrast, a moderate defense response mediated by pathogenesis related protein expression followed by significant upregulation of cell wall-related genes induced by ROS was a very effective defense against PWN infection (Hirao et al. 2012). In similar research by Liu et al. (2017) studied the gene expression profiling between resistant and susceptible masson pines (P. massoniana) after inoculation with B. xylophilus. The resistant and susceptible phenotypes had a different defense mechanism in response to B. xylophilus. Detailed gene expression analysis suggested that terpenoids were prominent defense compounds against this nematode. Moreover, the higher activity of ROS-scavenging enzymes was effective to inhibit the death of resistant masson pines after PWN inoculation (Liu et al. 2017).

Earlier study revealed that genomic variants that introduce frameshift or stop codon mutations (i.e., high impact variants) could have serious effects on protein structures and functions (Palomares-Rius et al. 2015). High levels of possible loss of function may be related to proteolysis, which includes metalloendopeptidase activity, aspartictype endopeptidase activity, and cysteine-type endopeptidase inhibitor activity (Palomares-Rius et al. 2015). In our research, metalloendopeptidase activity (GO:0004222) and aspartic-type endopeptidase activity (GO:0004190) were also over-represented for avirulent populations. It was confirmed that the GO term of aspartic-type endopeptidase activity enriched as a down-regulated function led to the low feeding activity (Palomares-Rius et al. 2015; Tanaka et al. 2019). Moreover, other, specific activity, such as hydrolase activity (GO:0016820) was also overrepresented in possible loss-of-function variation. The fact that such variants are enriched in these genes may suggest that regions with such expansions are also subjected to changes in terms of point mutations or small insertions and deletions (Palomares-Rius et al. 2015).

It is known that peptidase families have a diverse range of biological roles, such as moulting, development, food digestion, and parasitism, in nematodes. Also in $B$. xylophilus, each gene in the expanded peptidase family has distinct role. This is a clear example of gene family evolution by gene duplication and functional divergence (Tanaka et al. 2019). Nematode peptidases, which hydrolyse polypeptides or proteins, participate in a wide range of molecular, biological, and cellular processes, such as a digestion of host proteins, moulting and embryonic development of the egg (Tanaka et al. 2019). The genome sequence of $B$. xylophilus revealed a large number of predicted peptidase genes ( 808 peptidase genes), representing the highest gene number among characterised nematode genomes. They include aspartic (106), metallo (230), cysteine (142), serine (170), threonine (13), unknown_32 (8), and unknown_69 (136) genes (Kikuchi et al. 2011; Tanaka et al. 2019). Moreover, according to Shinya et al. (2013) the GO analysis clearly showed the expansion of peptidases in the secretome of B. xylophilus. Especially, a large number of cysteine and aspartic peptidases were detected.

Based on these results and the previous study, one plausible explanation for the phenotypic differences between the virulent (high virulence and fast lifecycle) and avirulent (low virulence and slow lifecycle) populations is likely to be the lack of activities of effectors or digestive proteases. This could lead them to display low ingestion of nutrients and provoke a delay in development. Moreover, the effects of unique variations in specific genes could also be important in explaining the different ecological traits of avirulent populations (Palomares-Rius et al. 2015).

Our findings showed that the level of diversity in the $B$. xylophilus genome is high and comparable with that in other hyper-diverse organisms. We identified genes affected by genomic variation, and functional annotation of those genes indicated that some of them might have potential roles in pathogenesis. This comparative genome study with geographically distant $B$. xylophilus populations can facilitate understanding of the complex evolutionary/epidemic history of this pathogen. We believe that demonstrating genetic differences between virulent and avirulent populations will provide effective methods to distinguish these two nematode virulence forms at the molecular level. We hope that the presented data will facilitate a better understanding of molecular mechanisms of pine wilt disease and diagnose this nematode species. In turn, it may help to develop effective strategies for control of B. xylophilus. However, further research is needed to determine specific roles of these genes in the pathogenesis. 
Acknowledgements The authors sincerely thank Prof. Manuel Mota from the University of Évora, Portugal, and Dr. Yuko Takeuchi from Kyoto University, Japan, for providing us with live cultures of B. xylophilus isolates.

Funding This study was supported by the National Science Centre, Poland (Grant no. 2017/01/X/NZ9/01708).

Data availability Raw sequencing data presented in this paper are available under the NCBI Sequence Read Archive (SRA) accession number PRJNA630377.

\section{Compliance with ethical standards}

Conflict of interest The authors declare that they have no conflict of interest.

Ethical approval This article does not contain any studies with human participants or animals performed by any of the authors.

Informed consent All the authors have consent for publication.

Open Access This article is licensed under a Creative Commons Attribution 4.0 International License, which permits use, sharing, adaptation, distribution and reproduction in any medium or format, as long as you give appropriate credit to the original author(s) and the source, provide a link to the Creative Commons licence, and indicate if changes were made. The images or other third party material in this article are included in the article's Creative Commons licence, unless indicated otherwise in a credit line to the material. If material is not included in the article's Creative Commons licence and your intended use is not permitted by statutory regulation or exceeds the permitted use, you will need to obtain permission directly from the copyright holder. To view a copy of this licence, visit http://creativecommons.org/licenses/by/4.0/.

\section{References}

Aikawa T, Kikuchi T (2007) Estimation of virulence of Bursaphelenchus xylophilus (Nematoda: Aphelenchoididae) based on its reproductive ability. Nematology 9:371-377. https://doi. org/10.1163/156854107781352007

Aikawa T, Togashi K, Kosaka H (2003) Different developmental responses of virulent and avirulent isolates of the pinewood nematode, Bursaphelenchus xylophilus (Nematoda: Aphelenchoididae), to the insect vector, Monochamus alternatus (Coleoptera: Cerambycidae). Environ Entomol 32:96-102. https ://doi.org/10.1603/0046-225X-32.1.96

Akiba M, Ishihara M, Sahashi N, Nakamura K, Ohira M, Toda T (2012) Virulence of Bursaphelenchus xylophilus isolated from naturally infested pine forests to five resistant families of Pinus thunbergii. Plant Dis 96:249-252. https://doi.org/10.1094/ PDIS-12-10-0910

Alexa A, Rahnenfuhrer J (2018) topGO: enrichment analysis for gene ontology. R package version 2.34.0. https://doi.org/10.18129/ B9.bioc.topGO

Alexa A, Rahnenführer J, Lengauer T (2006) Improved scoring of functional groups from gene expression data by decorrelating GO graph structure. Bioinformatics 22:1600-1607. https://doi. org/10.1093/bioinformatics/btl140
Andrews S (2010) FastQC: a quality control tool for high throughput sequence data. https://www.bioinformatics.babraham.ac.uk/proje cts/fastqc. Accessed 6 Oct 2011

Bolger AM, Lohse M, Usadel B (2014) Trimmomatic: a flexible trimmer for illumina sequence data. Bioinformatics 30:2114-2120. https://doi.org/10.1093/bioinformatics/btu170

Bolla RI, Boschert M (1993) Pinewood nematode species complex: interbreeding potential and chromosome number. J Nematol 25:227-238

Cheng X, Xie P, Cheng F, Xu R, Xie B (2009) Competitive displacement of the native species Bursaphelenchus mucronatus by an alien species Bursaphelenchus xylophilus (Nematoda: Aphelenchida: Aphelenchoididae): a case of successful invasion. Biol Invasions 11:205-213. https://doi.org/10.1007/s1053 0-008-9225-2

Cutter AD, Jovelin R, Dey A (2013) Molecular hyperdiversity and evolution in very large populations. Mol Ecol 22:2074-2095. https://doi.org/10.1111/mec.12281

Ding X, Ye J, Lin S, Wu X, Li D, Nian B (2016) Deciphering the molecular variations of pine wood nematode Bursaphelenchus xylophilus with different virulence. PLoS One 11:e0156040. https://doi.org/10.1371/journal.pone.0156040

Espada M, Silva AC, Eves-van den Akker S, Cock PJA, Mota M, Jones JT (2016) Identification and characterization of parasitism genes from the pinewood nematode Bursaphelenchus xylophilus reveals a multi-layered detoxification strategy. Mol Plant Pathol 17:286-295. https://doi.org/10.1111/mpp.12280

Evans H, McNamara D, Braasch H, Chadouef J, Magnusson C (1996) Pest risk analysis (PRA) for the territories of the European Union (as PRA area) on Bursaphelenchus xylophilus and its vectors in the genus Monochamus. EPPO Bull 26:199-249. https://doi.org/10.1111/j.1365-2338.1996.tb00594.x

Figueiredo J, Simöes MJ, Gomes P, Barroso C, Pinho D, Conceiçäo L, Fonseca L, Abrantes I, Pinheiro M, Egas C (2013) Assessment of the geographic origins of pinewood nematode isolates via single nucleotide polymorphism in effector genes. PLoS One 8:e83542. https://doi.org/10.1371/journal.pone.0083542

Filipiak A (2015) Pathogenicity of selected isolates of the quarantine pinewood nematode Bursaphelenchus xylophilus to Scots pine (Pinus sylvestris L.). J Plant Prot Res 55:378-382. https://doi. org/10.1515/jppr-2015-0050

Filipiak A, Wieczorek P, Tomalak M (2017) Multiplex polymerase chain reaction for simultaneous detection and identification of Bursaphelenchus xylophilus, B. mucronatus and B. fraudulentus - three closely related species within the xylophilus group. Nematology 19:1107-1116. https://doi.org/10.1163/1568541100003110

Futai K (1980) Developmental rate and population growth of Bursaphelenchus lignicolus (Nematoda: Aphelenchiodidae) and $B$. mucronatus. Appl Entomol Zool 15:115-122

Futai K (2013) Pine wood nematode, Bursaphelenchus xylophilus. Annu Rev Phytopathol 51:61-83. https://doi.org/10.1146/annur ev-phyto-081211-172910

Gene Ontology Consortium (2004) The gene ontology (GO) database and informatics resource. Nucleic Acids Res 32:258-261. https:// doi.org/10.1093/nar/gkh036

Gravato-Nobre MJ, Evans K (1998) Plant and nematode surfaces: their structure and importance in host-parasite interactions. Nematologica 44:103-124

Hirao T, Fukatsu E, Watanabe A (2012) Characterization of resistance to pine wood nematode infection in Pinus thunbergiiusing suppression subtractive hybridization. BMC Plant Biol 12:207-212. https://doi.org/10.1186/1471-2229-12-13

Hu LJ, Wu XQ, Li HY, Wang YC, Huang X, Wang Y, Li Y (2020) BxCDP1 from the pine wood nematode Bursaphelenchus 
xylophilus is recognized as a novel molecular pattern. Mol Plant Pathol 21:923-935. https://doi.org/10.1111/mpp.12939

Ishida K, Hogetsu T, Fukuda K, Suzuki K (1993) Cortical responses in Japanese black pine to attack by the pine wood nematode. Can J Bot 71:1399-1405

Jones JT, Haegeman A, Danchin EGJ, Gaur HS, Helder J, Jones MGK et al (2013) Top 10 plant-parasitic nematodes in molecular plant pathology. Mol Plant Pathol 14:946-961. https://doi.org/10.1111/ mpp. 12057

Kikuchi T, Cotton JA, Dalzell JJ, Hasegawa K, Kanzaki N, McVeigh $P$ et al (2011) Genomic insights into the origin of parasitism in the emerging plant pathogen Bursaphelenchus xylophilus. Plos Pathog 7:e1002219. https://doi.org/10.1371/journal.ppat.1002219

Kiyohara T, Bolla RI (1990) Pathogenic variability among populations of the pinewood nematode, Bursaphelenchus xylophilus. Forest Sci 36:1061-1076

Li H, Durbin R (2009) Fast and accurate short read alignment with Burrows-Wheeler Transform. Bioinformatics 25:1754-1760. https://doi.org/10.1093/bioinformatics/btp324

Li R, Li Y, Fang X, Yang H, Wang J, Kristiansen K, Wang Y (2009) SNP detection for massively parallel whole genome resequencing. Genome Res 19:1124-1132. https://doi.org/10.1101/gr.08801 3.108

Li Z, Zhang Q, Zhou X (2016) A 2-Cys peroxiredoxin in response to oxidative stress in the pine wood nematode Bursaphelenchus xylophilus. Sci Rep 6:27438. https://doi.org/10.1038/srep27438

Li Y, Meng F, Deng X, Wang X, Feng Y, Zhang W, Pan L, Zhang X (2019) Comparative transcriptome analysis of the pinewood nematode Bursaphelenchus xylophilus reveals the molecular mechanism underlying its defense response to host-derived $\alpha$-pinene. Int J Mol Sci 20:911. https://doi.org/10.3390/ijms20040911

Li Y, Feng Y, Wang X, Cui J, Deng X, Zhang X (2020) Adaptation of pine wood nematode Bursaphelenchus xylophilus to $\beta$-pinene stress. BMC Genom 21:478. https://doi.org/10.1186/s12864-02006876-5

Liu Q, Wei Y, Xu L, Hao Y, Chen X, Zhou Z (2017) Transcriptomic profiling reveals differentially expressed genes associated with pine wood nematode resistance in Masson pine (Pinus massoniana Lamb.). Sci Rep 7:4693. https://doi.org/10.1038/s4159 8-017-04944-7

McLaren W, Gil L, Hunt SE, Riat HS, Ritchie GR, Thormann A, Flicek $P$, Cunningham F (2016) The Ensembl variant effect predictor. Genome Biol 17:122. https://doi.org/10.1186/s13059-016-0974-4

Mota MM, Vieira PC (2008) Pine wilt disease: a worldwide threat to forest ecosystems. Springer, Dordrecht

Mota MM, Braasch H, Bravo MA, Penas AC, Burgermeister W, Metge K, Sousa E (1999) First report of Bursaphelenchus xylophilus in Portugal and in Europe. Nematology 1:727-734. https://doi. org/10.1163/156854199508757

Nose M, Shiraishi S (2011) Comparison of the gene expression profiles of resistant and non-resistant Japanese black pine inoculated with pine wood nematode using a modified Long SAGE technology. For Pathol 41:143-145. https://doi.org/10.111 1/j.1439-0329.2010.00646.x

Palomares-Rius JE, Tsai IJ, Karim N, Mitsuteru A, Kato T, Maruyama H, Takeuchi Y, Kikuchi T (2015) Genome-wide variation in the pinewood nematode Bursaphelenchus xylophilus and its relationship with pathogenic traits. BMC Genom 16:845. https:// doi.org/10.1186/s12864-015-2085-0

Pereira F, Moreira C, Fonseca L, van Asch B, Mota M, Abrantes I, Amorim A (2013) New insights into the phylogeny and worldwide dispersion of two closely related nematode species, Bursaphelenchus xylophilus and Bursaphelenchus mucronatus. PLoS One 8:e56288. https://doi.org/10.1371/journal.pone.0056288

Qiu X, Wu X, Huang L, Tian M, Ye J (2013) Specifically expressed genes of the nematode Bursaphelenchus xylophilus involved with early interactions with pine trees. PLoS One 8:e78063. https://doi. org/10.1371/journal.pone.0078063

Robertson L, Cobacho Arcos S, Escuer M, Santiago Merino R, Esparrago G, Abelleira A, Navas A (2011) Incidence of the pinewood nematode Bursaphelenchus xylophilus Steiner \& Buhrer, 1934 (Nickle, 1970) in Spain. Nematology 13:755-757. https://doi. org/10.1163/138855411X578888

Santos CS, Pinheiro M, Silva AI, Egas C, Vasconcelos MW (2012) Searching for resistance genes to Bursaphelenchus xylophilus using high throughput screening. BMC Genom 13:599. https:// doi.org/10.1186/1471-2164-13-599

Shinya R, Morisaka H, Takeuchi Y, Ueda M, Futai K (2010) Comparison of the surface coat proteins of the pine wood nematode appeared during host pine infection and in vitro culture by a proteomic approach. Phytopathology 100:1289-1297. https://doi. org/10.1094/PHYTO-04-10-0109

Shinya R, Takeuchi Y, Ichimura K, Takemoto S, Futai K (2012) Establishment of a set of inbred strains of the pine wood nematode, Bursaphelenchus xylophilus (Aphelenchida: Aphelenchoididae), and evidence of their varying levels of virulence. Appl Entomol Zool 47:341-350. https://doi.org/10.1007/s13355-012-0124-8

Shinya R, Morisaka H, Kikuchi T, Takeuchi Y, Ueda M, Futai K (2013) Secretome analysis of the pine wood nematode Bursaphelenchus xylophilus reveals the tangled roots of parasitism and its potential for molecular mimicry. PLoS One 8:e67377. https://doi. org/10.1371/journal.pone.0067377

Sommer RJ, Streit A (2011) Comparative genetics and genomics of nematodes: genome structure, development, and lifestyle. Ann Rev Genet 45:1-20. https://doi.org/10.1146/annurev-genet-11041 $0-132417$

Spiegel Y, McClure MA (1995) The surface coat of plant-parasitic nematodes: chemical composition, origin, and biological role-a review. J Nematol 27:127-134

Tanaka S, Dayi M, Maeda Y, Tsai I, Tanaka R, Bligh M, TakeuchiKaneko Y, Fukuda K, Kanzaki N, Kikuchi T (2019) Stage-specific transcriptome of Bursaphelenchus xylophilus reveals temporal regulation of effector genes and roles of the Dauer-like stages in the lifecycle. Sci Rep 9:6080. https://doi.org/10.1038/s4159 8-019-42570-7

Togashi K, Shigesada N (2006) Spread of the pinewood nematode vectored by the Japanese pine sawyer: modeling and analytical approaches. Popul Ecol 48:271-283. https://doi.org/10.1007/ s10144-006-0011-7

Tomalak M, Filipiak A (2013) Inter-specific competition of Bursaphelenchus xylophilus with native populations of B. mucronatus in pine. In: Schröder T (ed) Pine Wilt Disease Conference, Braunschweig, pp 70-71

Van der Auwera GA, Carneiro MO, Hartl C, Poplin R, Del Angel G, Levy-Moonshine A, Jordan T, Shakir K, Roazen D, Thibault J, Banks E, Garimella KV, Altshuler D, Gabriel S, DePristo MA (2013) From FastQ data to high confidence variant calls: the Genome Analysis Toolkit best practices pipeline. Curr Protoc Bioinform 43:11. https://doi.org/10.1002/0471250953.bi1110s43

Vicente CSL, Nascimento F, Espada M, Barbosa P, Mota M, Glick BR, Oliveira S (2012) Characterization of bacteria associated with pinewood nematode Bursaphelenchus xylophilus. PLoS One 7:e46661. https://doi.org/10.1371/journal.pone.0046661

Vicente CSL, Ikuyo Y, Shinya R, Mota M, Hasegawa K (2015) Catalases induction in high virulence pine wood nematode Bursaphelenchus xylophilus under Hydrogen Peroxide-Induced stress. PLoS One 10:e0123839. https://doi.org/10.1371/journ al.pone.0123839

Wang Y, Yamada T, Sakaue D, Suzuki K (2005) Variations in life history parameters and their influence on rate of population increase of different pathogenic isolates of the pine wood nematode, 
Bursaphelenchus xylophilus. Nematology 7:459-467. https://doi. org/10.1163/156854105774355545

Wood DE, Salzberg SL (2014) Kraken: ultrafast metagenomics sequence classification using exact alignments. Genome Biol 15:R46. https://doi.org/10.1186/gb-2014-15-3-r46
Publisher's Note Springer Nature remains neutral with regard to jurisdictional claims in published maps and institutional affiliations. 